\title{
Enabling Knowledge Sharing Practices for Academic and Research in Higher Education Institutions.
}

\author{
Dorothy Njiraine, $\mathrm{PhD}$ \\ University of Nairobi, Department of Library and Information Science, P.O. Box 30197-00100 Nairobi, Kenya.
}

\begin{abstract}
This paper underscores the need for knowledge sharing practices as an enabler for enhancing academic and research activities in Higher education institutions (HEIs). Despite the various HEIs availing support driven digital infrastructure to open and free access of information (digital resources) to academic and research community, the uptake and adoption of knowledge sharing practices is not evident enough to measure up the initiatives. Lecturers, researchers and scholars in HEIs need to embrace knowledge sharing in pursuit of innovation, recognition and competiveness. The paper therefore highlights the benefits of knowledge sharing as well as obstacles it faces. This paper applied content analysis in terms of review of both print and electronic resources as methodology based on identified objectives. The review found out that knowledge sharing is key to innovation but has not been fully embraced by the intended community as should. The paper suggests a number of ways in which knowledge sharing can be effected in HEIs. Major recommendations included aggressive sensitization on benefits of sharing knowledge and incentives not only to the targeted but also to stakeholders. The study also recommends a dedicated office for research coordination, collaboration, networking and visibility purposes. The paper proposes future research into investigating institutionalization and integration of knowledge sharing and possible approaches that would encourage voluntary knowledge generation and intrasharing amongst academics in HEIs.
\end{abstract}

Keywords: knowledge management, knowledge sharing, higher education institutions, academics, lecturers, researchers, scholars.

DOI: $10.7176 / \mathrm{IKM} / 9-3-09$

Publication date:March $31^{\text {st }} 2019$

\section{Introduction and background}

Higher education institutions are driven by globalization (OECD 2009). Additionally higher education trains skilled workers and contributes to the research base and capacity for innovation that determine competitiveness in the knowledge-based global economy while facilitating international collaboration and cross-cultural exchange (OECD, (2009). the cross-border flow of ideas, students, faculty and financing, coupled with developments in information and communication technology, are changing the environment where higher education institutions function' (OECD, 2009; Okioga et al. 2014). Higher education institutions (HEIs) face many perennial pitfalls, including expanding and promoting equitable access, improving learning achievement, fostering educational quality and relevance, strengthening knowledge and technology transfer, and encouraging desired values, behaviors, and attitudes (World Bank, 2017: 8). On the other hand, knowledge-based organizations are essential to economic growth and sustainable competitive advantage (UNESCO, 2017: 3; Conner and Prahalad, 1996). Knowledge sharing brings forth sustainable competitive advantage which is fundamental for societal progress and development (Makori et al 2015; Njiraine \& LeRoux, 2011). The positive role of the higher education sector in building knowledge-based economies is strongly promoted by international organizations such as the World Bank, because investment in quality training and higher education generates major external benefits that are critical for knowledge-driven economic and social development (Ramady, 2010).

Studies on knowledge sharing have drawn interest both at international, regional and national perspectives, with gaps at national level focusing on academic and research output. Examples of recent international studies have covered conceptual model (Rayees, 2018), enablers and barriers (Ramjeawon \& Rowley, 2017), implications of knowledge sharing amongst UK academics (Fullwood \& Rowley, 2017; Fullwood \& Rowley 2018, Fullwood et al, 2013), a review of studies on knowledge sharing in higher education institutions (Al-Kurdi, et al, 2018) and patterns and trends of knowledge sharing (Goswami \& Agrawal, 2018).

Similar studies can be found in Africa some such as knowledge sharing behaviors on postgraduate students in Nigeria (Opeke \& Opele, 2014), Knowledge sharing strategies on traditional vegetables in Tanzania (Chipungahelo, 2015) and Knowledge sharing practices amongst academics in Zimbabwe (Chikono, 2018). 
Examples of Kenyan studies on knowledge sharing such as from indigenous knowledge perspective whereby it is easily shared with appropriate platforms (Njiraine et al, 2012, Chepchirchir et al, 2015, Kwanya, 2015), informal sector, commonly referred to as juakali on its competitiveness and sustainability (Wangare, 2015), as a support for effective service delivery in government (Ondari-Okemwa \& Gretchen 2009) and for competitive advantage in hospitality industry (Kiseli, J. (2016).

It is therefore important to enhance scientific knowledge creation and sharing processes in academia for significant transformation. Higher education institutions have been passive in exploiting their knowledge assets (Donate and Canales, 2012). Whereas there a strong body of research into knowledge management and knowledge sharing in both private and public sectors (Brown \& Brudney, 2003; Sandhu et al., 2011), research into knowledge management in universities is limited. Back in 2000, Rowley posed the question 'is higher education ready for knowledge management?' in other words since knowledge sharing is a crucial component of knowledge management, wouldn't it then be justified to question "is higher education ready for knowledge sharing?"

\section{Statement of the problem}

As lecturers teach, research, consult, and publish so are the exponential benefits to universities in terms of development of quality education and also improvement on the performance of university at large (Ali et al, 2014). Despite the various universities availing support driven digital infrastructure to open and free access of information (digital resources) to academic and research community, the uptake and adoption of knowledge sharing practices is not evident to measure up the initiatives. As Makori (2015: 19) argues the resistance to embrace utilization of digital information is a norm rather than an exception. This resistance needs to be addressed from individual, group and institutional perspectives to bear positive change. Other factors contributing to inadequate application of knowledge sharing practices by academics is the expanding student enrolment as well as new academic programmes in terms of developing appropriate strategies and innovations to meet the increasing students' information needs and other academic requirements (Nyaigotti-Chacha, 2004; Munene, 1997). Besides, universities need to recognize knowledge as a vital resource in management activities, for spurring growth and innovation (Njiraine \& LeRoux, 2011: 817; Rowley 2000: 329). It is also understood that knowledge management (knowledge sharing being a key component) is primarily about accessing appropriate knowledge and knowledge resources to appropriate people at appropriate time and in appropriate format. With this understanding, it only makes sense that knowledge sharing as a practice is perhaps the single most important aspect and the vast majority of knowledge management initiatives depend upon (Frost, 2014), yet inadequately applied. We argue that knowledge sharing spurs innovation, competitiveness, economic growth and key to global positioning of Higher education institutions through partnerships, networking, visibility and stakeholders' engagement.

\section{Methodology}

Review of related literature conducted in form of content analysis. It included both electronic and print resources subscribed by the University of Nairobi. The subscribed resources are discipline-specific while others multidisciplinary. The review was based on the following key words: knowledge sharing; information sharing; knowledge sharing practices; information sharing practices; resources sharing and resources sharing practices. A systemic literature review was approached methodically by identifying relevant key word as afore-indicated (Ali and Miller, 2017; Williams et al., 2015). Analysis included a brief write-up based on conceptualization of knowledge sharing practices as an enabler for academic and research output. This is the first phase of the study, which lays the foundation for phase two, to be carried out by use of questionnaires, interviews and focus group at a later stage in the year.

\section{Knowledge sharing conceptualization}

Whereas knowledge sharing is understood from diverse perspectives, Dixon (2000) argued it is all about common knowledge, with two meanings, to give away a part (an act of generosity) and also to have in common (shared belif system). He further contends that common knowledge leads to action which has both tacit and explicit components. This proves that knowledge sharing as a concept is complext and depends on the time, place and who to share.

On a similar note, Ho, (2009), contends that definitions of knowledge sharing exist according to perspectives, needs, situations, and circumstances, proving lack of a univesally accepted definition. Additionally knowledge 
sharing entails many elements, which include but not limited to: what kind of knowledge is shared; nature of sharing and the level of sharing, whether at individual, team, or organizational levels. In the work of Kuo, (2013), knowledge sharing is defined as "individuals sharing organizationally relevant information, suggestions, and expertise with one another", in addition other factors influencing effective knowledge sharing, which include relationship between knowledge source and knowledge recipients, forms and locations of knowledge, knowledge recipients' learning predisposition, knowledge sources' ability to share, and the environment in which knowledge sharing occurs.

Effective knowledge sharing brings about the transfer aspect, whereby appropriate transfer rate depends highly on the recipient. The recipient in this case being fellow lectures or the students should have enough absorptive capacity (Cohen and Levinthal, 1990). The understanding here is that for an individual or team to absorb the new knowledge, they must have already had previous related knowledge, setting familiarity, which in turns makes it easier for the individual/team have the basic skills such as ability to work together, shared language and technical language. This It is important to understand that different methods need to be used to enable different types of knowledge to be shared which is dependent on the context, the objectives of sharing knowledge and the type of complexity in the setting (Jonas, 2003).

Knowledge-sharing behaviors are influenced by different approaches and can happen under different situations. According to Alavi and Leidner (2014), there are four major approaches for individuals to share their knowledge in organizations: first, contribution of knowledge to organizational databases, such as institutional repositories; second, sharing knowledge in formal interactions within or across teams or work units; third, sharing knowledge in informal interactions among individuals; and fourth, sharing knowledge within communities of practice, which are voluntary forums of employees around a topic of interest.

Knowledge sharing can be done through partnerships outside organizations. It can generate positive externalities and enable organizations to capture spillover from partners (Jones et al., 2011). Moreover, knowledge of the cost structure and production options shared by partners helps organizations realize the constraints and therefore make the appropriate adjustments in their preferences for transfer projects (Jain, 2014).

External knowledge sharing across organizations is the strongest contributor to performance. Therefore, organizations must identify knowledge frontiers across which knowledge sharing is to take place. Knowledge can increase effectiveness only when it is shared with and transferred to others. Therefore, the ability and willingness of knowledge senders to share knowledge are crucial to knowledge effectiveness for knowledge recipients. Knowledge sharing across organizations is a starting point and a necessary element for mutual learning. After the sharing process, the collection of shared knowledge is acquired by knowledge recipients. Thereafter, it is utilized for their learning orientation. (Jones et al., 2011) state that learning orientation facilitates the generation of resources and skills essential for improving firm performance.

Knowledge sharing has numerous benefits (not limited) to any organization, see Onyancha, (2016); Miloff \& Vogelstein (2013) and OECD (2009) such as:

- Transparency in research for greater re-use of data.

- Effective information security practices.

- Increased cross-border collaboration in research (international co-authored articles have been on an increasing trend over the past two decades).

- Increased international funding for university research.

- Increased global competition and recognition through webometrics ranking.

- Enhancement of effectiveness and efficiency by spreading good ideas and practices.

- Cost effectiveness, knowledge is developed and then re-used by many people.

- $\quad$ Time savings, professionals learn from their mistakes and those of others.

- Emotional relief and decreased tension are experienced when problems are shared.

- Bonds and connections between professionals are strengthened; solving problems brings people together.

- More sophisticated ideas, insights and information sources are applied to problems resulting in better solutions.

- Innovation and discovery increase as does: excitement, engagement and motivation. 
- A feeling of satisfaction from sharing knowledge, much like giving charity, results from making a contribution to society.

- $\quad$ Respectful ways of using knowledge (with attribution and permission) benefit the person who generates the knowledge and the person who shares it.

Although sharing knowledge can be beneficial for the sharer in terms of enhanced reputation and expansion of influence, these benefits may not be persuasive enough when sharing one's knowledge is seen as costly (Casimir, et al, 2012).

\section{Contextualizing knowledge sharing}

Understanding that learning is the process of acquiring knowledge and skill then it is imperative to say that learning, teaching and training activities are directly linked to the development of both individual and organizational knowledge (Garvin, 1993). The same applies to constituents of universities, the knowledge workers and their communities of practices whereby they should learn and learn to learn. Communities of practice are instrumental in the learning process. It is by this understanding that they must keep learning together in order to attain the development of individual and organizational competitiveness. To encourage learning in action, Knowledge Management (KM) effectively supports problem-based learning and learning by doing. For knowledge workers in the universities, KM provides them a learning environment supporting their academic research tasks. Hence, in this way, they are able to share with others their research experiences and findings, knowledge sharing platforms and practices appropriate model for spearheading the practice for the benefit of the university.

Knowledge sharing is argued as a key activity of any effective knowledge management in any organization (Amayah, 2013; Gururajan \& Fink, 2010; Olatokun and Nwafor, 2012). In order for knowledge to be utilized once it is created, thereby providing value to the organization, it must be shared with colleagues, teammates, and co-workers. Paulin and Suneson (2012) identify the following factors that influence knowledge sharing as; the nature of knowledge; the motivation to share; the opportunities to share the culture and the work environment. The sharing and transferring of knowledge is very vital to knowledge management, given the fact that organizations struggle with knowledge loss resulting from employee turnover.

Knowledge sharing and transfer are important factors influencing the processes of innovation and competitiveness (Avdimiotis, 2012). For any organization, the ultimate goal of managing knowledge is to increase profit by improving the efficiency of operations, increasing the quality and quantity of innovations, and enhancing competitiveness. However, this desired benefit cannot be achieved without knowledge collected being effectively applied within the organization. Therefore, employees at all levels of organization need to make a systematic effort to utilize the knowledge available at different points of their activities, such as decision making. The organization's ability to apply its knowledge to critical business activities serves as the key link between the business goals of a knowledge management program and its actual, realized benefits. Reusing knowledge inevitably requires the active participation of knowledge workers, typically organized in work groups in an organization (Hislop, 2013).

Although sharing knowledge can be beneficial for the sharer in terms of enhanced reputation and expansion of influence, these benefits may not be persuasive enough when sharing one's knowledge is seen as costly (Casimir, et al, 2012).

Knowledge sharing across organizations is a starting point and a necessary element for mutual learning. After the sharing process, the collection of shared knowledge is acquired by knowledge recipients. Thereafter, it is utilized for their learning orientation. (Jones et al., 2011) postulate that learning orientation facilitates the generation of resources and skills essential for improving firm performance and also enhances co-production. They further explain that co-production is constructive participation in the creation and delivery process that requires meaningful and cooperative contributions to the process. Jain 2014; Mohr and Bitner, 1991; Jones et al., 2011) argue that co-production across organizations fosters a climate of reciprocity, in addition to organizations being involved in co-production move toward increased mutual understanding, which results in positive outcomes.

Sharma and Patterson (2013) also argue that joint decision making can increase the quality of shared knowledge and help one better understand the needs of the other. Thus, knowledge recipients should engage in this process. 
In effect, they become co-producers, and such joint planning and joint problem solving offer them access to the knowledge stock of partners (Jain, 2014).

Knowledge sharing is central in establishing strong relationships (Sharma and Patterson, 2013). It enables organizations to interact more, hence enhancing mutual understanding and establishes the foundation for coordination (Jones et al., 2011) and collaboration (Jain, 2014). Similarly, knowledge sharing increases the incidence of co-production (Jones et al., 2011), which reflects a process dimension of a relational governance mechanism that involves carrying out focal activities by both parties in a cooperative or coordinated way.

To sum it all, in the growing global economy managing knowledge effectively has become a source of competitive advantage. Companies are adopting integrated approaches to identify, manage, share and capitalize on the know-how, experience and intellectual capital of employees. Knowledge audit and subsequent knowledge sharing can never be ignored as frontiers in ensuring that organizations optimize and realize their mandate efficiently and effectively.

\section{Pitfalls}

There are several factors that affect knowledge sharing in organizations. According to Hong, et al, (2011) these include lack of time to share knowledge; concern about hazard job security; little awareness; dominance of explicit knowledge over tacit knowledge in sharing; inadequate capture, evaluation, and communication of previous mistakes that may improve individual and organizational learning influences; differences in experience levels; lack of interaction, social network; poor communications and interpersonal skills; age, gender, cultural, and educational differences and little trust to the accuracy and credibility of knowledge due to the sources.

Facilitating tacit knowledge sharing among individuals, such as the sharing of experiences, skills, know-how, or know-whom, and also retaining this knowledge in organizational memory has always been of interest to organizations (Taylor, 2006) hence the need for organizations to foster healthy organizational culture that promotes knowledge sharing. However, finding the right conditions, incentives, and mechanisms for sharing this unstructured knowledge according to Allen (2008), has long been a major issue of organisations and knowledge management research. Another major problem faced by organizations is that many employees lack the desire to share their knowledge with other members of the organization (Denning, 2006). How individuals feel about their organization and colleagues is also a critical determinant of knowledge sharing (Liebowitz, 1999; Soliman and Spooner, 2000) as is the perceived costs of sharing one's knowledge: For instance, time and effort, and loss of expert power. Taking most higher education institutions organizational structures, three components of academic affairs, students' docket and the research, are the most appropriate to foster knowledge sharing for academic and research activities.

\section{Conclusion}

Knowledge Sharing depends on the culture and willingness of the knowledge worker to seek out and be receptive to these organization's knowledge sources. The appropriate organization culture, incentives, should be present. Facilitation of knowledge sharing can only be effective if organizations understand the needs of the users, as well as the complexities and potential problems with managing knowledge and knowledge sources. Others like Chen and Cheng (2011) conducted a study on the organizational and personal factors motivating employees to share knowledge. Their study also revealed that internal marketing, internal communication, leadership, management support, inter-departmental interaction, training and openness, organizational culture ,cooperation and trust among staff, fairness and social network influence knowledge sharing practices.

Successful knowledge and innovation management begins with a sound strategy combined with fostering of organizational culture that enables and rewards the sharing of valuable knowledge. While technology is important to facilitate knowledge sharing and collaboration, more attention needs to be paid to its content and use. It also cannot replace important face-to-face interactions. To promote knowledge sharing, there is need to look at it holistically through learning circles, networking, peer-to-peer assistance, improved interactions and mutual learning. The concrete personal relationships and networks that are created through this process are a basis for trust. Knowledge flows when people perceive there is a climate of trust, which is one of the key prerequisites of culture that promotes knowledge management and innovation. The social capital that is strengthened in such an environment needs to be maintained through continuous investment in learning and development. Together with appropriate incentives, this would help create a collaborative and knowledgesharing culture, without which knowledge cannot be managed effectively and innovations cannot be properly documented, shared and applied in new contexts. 


\section{Recommendations and further research}

Broadly speaking, organizations should therefore, implement appropriate processes, policies, and systems that enhance knowledge sharing in terms of embracing technology (Njiraine, 2012). HEIs, for instance, have increased their research and access to materials through the use of information technology. They must also foster a knowledge sharing culture and strategies such as organizational structural styles, organizational strategies, communication, trust, motivations, learning and training can be considered as factors that influence creating and sharing knowledge culture. The study also recommends a dedicated office for research coordination, collaboration, networking and visibility purposes and future research targeting the researchers, lecturers' students and other stakeholders in order to get an in-depth of knowledge sharing practices. Additionally, higher education institutions should adopt an aggressive role to sensitize academic staff and reward those embracing it.

The following areas need further research:

- Exploring mechanisms of institutionalization and integration of knowledge sharing in policies and strategies by HEIs as enablers for increased academic and research output.

- Investigate appropriate approaches that would encourage academics to voluntarily generate and intra-share knowledge in HEIs.

\section{References}

Alavi, M., \& Leidner, D. (2014). Knowledge management and knowledge management systems: Conceptual foundations and research issues. MIS Quarterly, 25(1), 107-136.

Allen, K. (2008). Developing trends and challenges for the information industry examined in the context of the Online Information Conference. Business Information Review, 25 (2), 81-85.

Al-Kurdi, O., El-Haddadeh, R. \& Eldabi, T. (2018). Knowledge sharing in higher education institutions: A systematic review. Journal of Enterprise Information Management, 31 (2), 226-246.

Ali, K., Khani, N \& Yusoff, R. (2014). Factors affecting knowledge sharing intention among academic staff. International Journal of Educational Management, 28 (4), 413 - 43.

Denning, S. (2006). Effective storytelling: Strategic business narrative techniques. Strategy \& Leadership, 34 (1), $42-48$.

Goswami, A \& Agrawal, R. (2018). A reflection on knowledge sharing research: Patterns and trends. VINE Journal of Information and Knowledge Management Systems, 48 (3), 352-372.

Brown, M. and Brudney, J. (2003), “Learning organizations in the public sector? A study of police agencies employing information and technology to advance knowledge', Public Administration Review, Vol. 63 No. 1, pp. 30-43.

Casimir, G., Lee, K., and Loon, M. (2012). Knowledge sharing: influences of trust, commitment and cost. Journal of Knowledge Management, 16(5), 740-753.

Cheng, M.; Ho, J. \& Lau, P. (2009). Knowledge sharing in academic institutions: A study of Multimedia University Malaysia. Electronic Journal of Knowledge Management, 7 , (3), 313-24.

Chepchirchir, S, Kwanya, T. \& Kamau, A. (2018). Maximising the socioeconomic value of indigenous knowledge through policies and legislation in Kenya. Global Knowledge, Memory and Communication.

Chikono, A. (2018). Knowledge sharing practices amongst academics at the Zimbabwe Open University. Unpublished dissertation. University of Western Cape. South Africa

Chipungahelo, M. (2015). Knowledge sharing strategies on traditional vegetables for supporting food security in Kilosa District, Tanzania. Library Review, 64 (3), 229-247.

Conner, K. and Prahalad, C. (1996), A resource-based theory of the firm: knowledge versus opportunism. Organization Science, 7 (5), 477-501.

Donate, M. \& Canales, J. (2012). A new approach to the concept of knowledge strategy. Journal of Knowledge Management, 16 (1), 22-44.

Farooq, R. (2018). A conceptual model of knowledge sharing. International Journal of Innovation Science, 10 (2), 238-260.

Fullwood, R. \& Rowley, J. (2017). An investigation of factors affecting knowledge sharing amongst UK academics. Journal of Knowledge Management, 21 (5), 1254-1271.

Fullwood, R., Rowley, J \& Delbridge, R. (2013). Knowledge sharing amongst academics in UK universities. Journal of Knowledge Management, 17 (1), 123 - 136.

Garvin, D. (1993). Building a Learning Organisation. Harvard Business Review, Reprint 93402. 
Goswami, A \& Agrawal, R. (2018). A reflection on knowledge sharing research: Patterns and trends. VINE Journal of Information and Knowledge Management Systems, 48 (3), 352-372.

Ho, C. (2009). Knowledge sharing: game and reasoned action perspectives. Industrial Management \& Data Systems Vol. 109(9), 1211-1230.

Hislop, D. (2009), Knowledge Management in Organizations, 2nd ed., Oxford University Press, Oxford.

Hong, D., Suh, E., \& Koo, C. (2011) Developing strategies for overcoming barriers to knowledge sharing based on conversational knowledge management: A case study of a financial company. Expert Systems with Applications, 38, PP.14417-14427.

Jain, P. (2014). Review: Knowledge Management and Knowledge Management Systems: Conceptual Foundations and Research Issues. U.S.A

Jones, C., Hesterly, W.S. and Borgatti, S.P. (2011). A general theory of network governance: exchange conditions and social mechanisms, Academy of Management Review, 22 (4), 911-945.

Kinengyere, A. (2007). The effect of information literacy on the utilization of electronic information resources in selected academic and research institutions in Uganda. The Electronic Library, 25 (3), 328-341.

Liebowitz, J. (1999). Key ingredients to the success of an organization's knowledge management strategy. Knowledge and Process Management, 6, (1), 37-40.

Makori, E. (2015). Micro factors influencing use of electronic information resources among postgraduate students in institutions of higher learning in Kenya. Library Hi Tech News, 32 (1) 18-21.

Makori, E., Njiraine, D. \& Talam, P. (2015). Practical aspects of implementation of institutional repositories in Africa with reference to the University of Nairobi. New Library World, 116 (9/10), 610-640.

Munene, I. (1997). The struggle for faculty unionism in a stalled democracy: Lessons from Kenya's public Universities. Journal of the Third Word Studies. 14 (1), 91-114.

Njiraine, D. (2012). Mapping and auditing indigenous knowledge and its management environment: A comparative study of Kenya and South Africa. Saarbrücken (Germany): Lambert Academic Publishing.

Njiraine, D \& LeRoux. (2011). Applying Earl's KM model in IK management: With reference to Kenya and South Africa. The Electronic Library, 29 (6), 817- 827.

Njiraine, D; Ocholla, D.N \& Onyancha, B. (2011). Indigenous knowledge research in Kenya and South Africa: An informetrics study, a chapter (Chapter 7, pgs. 90 - 104) in D. Ocholla \& J. s Britz (Eds.) Research issues in Information Studies in a changing local and global environment: Some African perspectives. Saarbrücken, Germany: Lambert Academic Publishing.

Nyaigotti-Chacha, C. (2004). Reforming higher education in Kenya: Challenges, lessons and opportunities. Naivasha: state university of New York workshop with the parliamentary committee on education, science and technology, August. 2004

OECD. (2009). Globalisation and higher education: what might The future bring?: Educational Research and Innovation Higher Education to 2030 (Vol. 2). Paris: OECD.

Okioga, C.; Onsongo, E. \& Nyaboga, Y. (2014). Quality issues in the expansion of university education in Kenya, The human resource challenges and opportunities', Chinese business review, Vol. 11, No. 6, Pp. 596-605.

Olatokun, W. and Nwafor, C. I. (2012). The effect of extrinsic and intrinsic motivation on knowledge sharing intentions of civil servants in Ebonyi state, Nigeria. Information Development, 28(3), 216-234.

Ondari-Okemwa, E \& Gretchen, J. (2009). The role of knowledge management in enhancing government Service-delivery in Kenya. South African Journal of Library and Information Science, 75 (1).

Onyancha, O. (2016). Open Research Data in Sub-Saharan Africa: A Bibliometric Study Using the data citation index. In open access movement and the future of Africa is knowledge economy. Fourth CODESRIA Conference on Electronic Publishing (pp. 1-18). Dakar, Senegal.

Opeke O. \& Opele K. (2014). Assessment of Knowledge sharing Behaviours of Postgraduate Students in Selected Nigerian Universities. Information and Knowledge Management, 4 (11), 102-106.

Paulin, D. and Suneson, K. (2012) Knowledge Transfer, Knowledge Sharing and Knowledge Barriers: three Blurry terms in KM . The Electronic Journal of Knowledge Management Volume 10, Issue 1, pp. 81-91.

Ramjeawon, P. \&Rowley, P. (2018). Knowledge management in higher education institutions in Mauritius. International Journal of Educational Management, 32 (7), 1319-1332.

Ramjeawon, P. \& Rowley, J. (2017). Knowledge management in higher education institutions: Enablers and barriers in Mauritius. The Learning Organization, 24 (5), 366-377.

Rayees Farooq, (2018) "A conceptual model of knowledge sharing", International Journal of Innovation Science, Vol. 10 Issue: 2, pp.238-260

Rowley, J. (2000). Is higher education ready for knowledge management? International Journal of Education Management, 14 (7), 325-33.

Sandhu, M., Jain, K. and Ahmad, I. (2011), “Knowledge sharing among public sector employees: Evidence from Malaysia', International Journal of Public Sector Management, Vol. 24 No. 3, pp. 206-26. 
Sharma, N. and Patterson, P.G. (2013), The impact of communication effectiveness and service quality on relationship commitment in consumer, professional services, Journal of Services Marketing, 13(2), 151170.

Soliman, F and Spooner, K. Strategies for implementing knowledge management: role of human resources management. Journal of Knowledge Management, 4 (4), 337-345.

Taylor, J. (2006). Big is beautiful: Organisational change in universities in the United Kingdom: new models of institutional management and the changing role of academic staff. Higher Education in Europe, 31 (3), 251-71.

UNESCO. (2017). Mapping of the status of cultural Indicators and statistics in East Africa. nd: np.

Wangare, B. (2015). Knowledge management in the informal sector: A review of the Kenya's jua kali sector. International Journal of Economics, Commerce and Management, 3 (10), 257-278.

World Bank. (2017). Higher education for development: An evaluation of the World Bank Group's Support. Washington: International Bank for Reconstruction and Development.

World Bank. (2017). Higher education for development: An evaluation of the World Bank Group's Support. Washington: International Bank for Reconstruction and Development.

Williams, M., Rana, N. \& Dwivedi, Y. (2015). The unified theory of acceptance and use of technology (UTAUT): A literature review. Journal of Enterprise Information Management, 28 (3), 443-488.

\section{Author}

Dorothy Njiraine is the Chairperson and Lecturer, Department of Library and Information Science, University of Nairobi, Kenya. She holds a Doctorate of Library and Information Science (University of Zululand, South Africa -2011), MSc. in Information Science (Makerere University, Uganda -2005), MBA (Moi University, Kenya -2012), PGD in Librarianship (Makerere University, Uganda - 1998) and B.A. Hons (University of Nairobi, Kenya - 1989). She is also a member of Kenya Library Association.

Research interests: Knowledge management; Indigenous knowledge; Indigenous knowledge systems; ICT4D; Agricultural information and communication management; Digital libraries and information systems; Management information systems; Information literacy and communication skills Information ethics; Bibliometrics; Informetrics; Strategic management; Human resource management; Project planning and management; Research methods. 